\title{
Development of Seismic Collapse Capacity Spectra and Parametric Study
}

\author{
Wei Shi', Xinzheng Lu ${ }^{1, *}$, Hong Guan ${ }^{2}$ and Lieping $\mathrm{Ye}^{1}$ \\ ${ }^{1}$ Key Laboratory of Civil Engineering Safety and Durability of China Education Ministry, \\ Department of Civil Engineering, Tsinghua University, Beijing, China \\ ${ }^{2}$ Griffith School of Engineering, Griffith University Gold Coast Campus, Queensland 4222, Australia
}

(Received: 14 August 2013; Received revised form: 6 January 2014; Accepted: 26 March 2014)

\begin{abstract}
Single-Degree-of-Freedom (SDOF) systems are widely used to investigate the collapse resistance of building structures. A SDOF model capable of representing the key properties associated with earthquake-induced collapse is outlined in this study. The seismic collapse capacity of SDOF systems is evaluated via an incremental dynamic analysis, based on which the collapse capacity spectrum is developed. The computational procedure and engineering significance of the collapse capacity spectrum are elaborated in some detail. The influence of various structural properties on the collapse resistance of SDOF structural systems is also comprehensively discussed, which include fundamental period, ductility ratio, post-capping stiffness, hysteretic pinching, cyclic deterioration and $P-\Delta$ effect. Furthermore, the influence of ground motion features on the collapse resistance of SDOF systems is examined by using the proposed collapse capacity spectrum.
\end{abstract}

Key words: collapse, spectrum, SDOF, incremental dynamic analysis, ground motion.

\section{INTRODUCTION}

Published records of earthquake events indicate that the collapse of structures is the primary cause of casualties (Zhao et al. 2009; DesRoches et al. 2011) and property losses (Brookshire et al. 1997; Kircher et al. 1997) during and after severe earthquakes. As such, preventing earthquake-induced collapse has always been a major objective of seismic design (Krawinkler and Zareian 2007; Ye et al. 2010). Earthquake-induced collapse refers to the loss of ability of a structural system, or any part thereof, to resist tributary gravity loads in the presence of earthquake action (Krawinkler and Zareian 2007). Observations of collapsed buildings during earthquake events reveal that two modes of global collapse can occur for a moment frame: sidesway collapse and vertical collapse (Zareian and Krawinkler 2010). Sidesway collapse occurs due to the combination of excessive deformation and successive reduction of load carrying capacity of the building's lateral force resisting system (or part of it), to the extent that the second-order $P-\Delta$ effects fully offset the firstorder inter-story shear resistance thereby causing dynamic instability. Vertical collapse, on the other hand, is triggered by the direct loss of gravity load carrying capacity in one or several structural components. Comparing these two collapse modes, the sidesway collapse mode is preferable because it offers more ductility during the collapse process than does the vertical collapse mode. Therefore, a sidesway collapse mode-oriented design is specified in many design codes (e.g., strong-column-week-beam mechanism) and this collapse mode is the focus of this study.

With rapid development of numerical simulation techniques and computational power, the collapse fragility evaluation approach based on incremental dynamic analysis (IDA) (Vamvatsikos and Cornell 2002 , 2004) has become increasingly popular. It provides a probabilistic-based methodology to 
quantitatively evaluate the collapse capacity of structural systems and therefore enables more accurate estimation of earthquake-induced losses within the framework of performance-based earthquake engineering (Goulet et al. 2007; Zareian and Krawinkler 2007; Zareian et al. 2010). Indeed, the IDAbased collapse fragility evaluation approach has been used worldwide to assess the seismic collapse capacity of structural systems in order to improve the collapse safety design (Luco et al. 2007; FEMA 2009; Haselton et al. 2010; Liel et al. 2010; Tang et al. 2011; Lu et al. 2012). Nevertheless, a rigorous IDA-based collapse fragility evaluation approach is computationally demanding that has prompted many researchers seeking simplified, approximate and practical methods to assess the collapse resistance of structures (Han et al. 2010; Shafei et al. 2011; Fajfar and Dolšek 2011). Amongst these approximate procedures, the static pushoverbased methods are found to be more attractive. This is due to their ability of relating the collapse performances of a multiple-degree-of-freedom (MDOF) system with an equivalent single-degree-of-freedom (SDOF) system via a static pushover analysis, which has been popularly used in engineering applications with proven success during the past decades. For example, Fajfar and Dolšek (2011) proposed a practice-oriented estimation of the failure probability of building structures, utilizing a pushover-based N2 method to reduce the computational time. Similarly, Han et al. (2010) developed a modal pushover analysis (MPA)-based approximate procedure to quantify the collapse potential of structural systems, in which the first-mode SDOF system was considered adequate and higher modes of vibration were found to be insignificant in estimating the ground motion intensity required to cause collapse of the structure. It should be noted that a large number of simple structures (e.g. water towers, single-story buildings and multi-story regular buildings) can be simplified into the SDOF systems when their seismic collapse resistance is to be evaluated (e.g., Miranda and Akkar 2003; Vian and Bruneau 2003). In addition, professional practice also favors simplified methods, mostly using SDOF models, that approximate the behavior of MDOF systems by matching their static pushover curves, to examine the collapse resistance of structural systems (Takizawa and Jennings 1980; Williamson 2003; Vamvatsikos and Cornell 2005; Han et al. 2010; Fajfar and Dolšek 2011). In view of this, seismic collapse capacities of SDOF systems deserve being systematically investigated.

This study utilizes the IDA-based collapse fragility evaluation approach to assess the seismic collapse capacity of SDOF systems and proposes the concept of collapse capacity spectrum. The embryonic concept of collapse capacity spectrum can be dated back 20 years (Bernal 1992). Ibarra and Krawinkler (2011) discussed the variance of collapse capacities of SDOF systems under earthquake excitations in the context of collapse capacity spectrum. In addition, Adam and Jäger employed the collapse capacity spectrum to study the $P-\Delta$ effect (Adam and Jäger 2012) and near-field effects on the collapse capacity of SDOF systems (Jäger and Adam 2013). In this paper, the computational procedure and engineering significance of the collapse capacity spectrum are elaborated in further detail. In the context of collapse capacity spectrum, the influence of various structural properties on the collapse resistance of SDOF structural systems is also comprehensively discussed, which include fundamental period, ductility ratio, postcapping stiffness, hysteretic pinching, cyclic deterioration and $P-\Delta$ effect. Furthermore, the influence of ground motion features on the collapse resistance of SDOF structures is also discussed using the proposed collapse capacity spectrum.

\section{HYSTERETIC MODEL}

An adaptive hysteretic model that can simulate the major features of various structures is very important for collapse assessment. The hysteretic model used to evaluate the collapse resistance is described in this section. Noting that the cyclic strength and stiffness deterioration are key concerns in collapse prediction (Krawinkler and Zareian 2007), the hysteretic model proposed by Ibarra et al. (2005) is adopted herein. The restoring force (denoted as $F$ ) versus displacement (denoted as $D$ ) relationship of the SDOF system is represented by a modified Clough model (Clough and Johnston 1966; Mahin and Bertero 1976) with a trilinear capped backbone curve. Moreover, to comprehensively study the collapse resistance of SDOF systems, such factors as the pinching effect, cyclic deterioration of strength and stiffness and the $P-\Delta$ effect should also be incorporated into the hysteretic model.

As illustrated in Figure 1(a), the initial backbone curve is defined by five parameters: (i) the elastic stiffness $K_{\mathrm{e}}$, (ii) the yield strength $F_{\mathrm{y}}$, (iii) the hardening ratio $\alpha_{\mathrm{s}}$ that defines the post-yielding stiffness $K_{\mathrm{s}}$ as $K_{\mathrm{s}}$ $=\alpha_{\mathrm{s}} K_{\mathrm{e}}$, (iv) the ductility ratio $\mu$ that characterizes the capping deformation $D_{\mathrm{c}}$ as $D_{\mathrm{c}}=\mu D_{\mathrm{y}}=\mu F_{\mathrm{y}} / K_{\mathrm{e}}$, where $D_{\mathrm{y}}$ is the yield displacement, and (v) the softening ratio $\alpha_{\mathrm{c}}$ that defines the stiffness of the post-capping branch (denoted as $K_{\mathrm{c}}$ ) as $K_{\mathrm{c}}=-\alpha_{\mathrm{c}} K_{\mathrm{e}}$. The modified Clough model (i.e., the maximum historical displacementoriented model) is adopted as the basic hysteretic rule, as displayed in Figure 1(b), where the serial numbers indicate the loading history. 


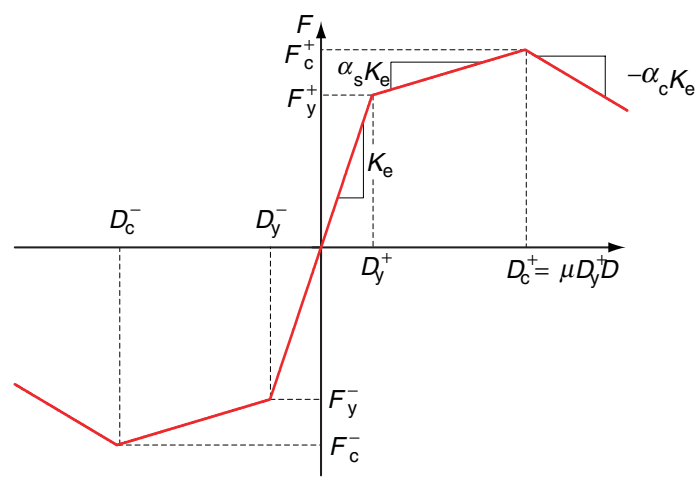

(a) Trilinear backbone curve

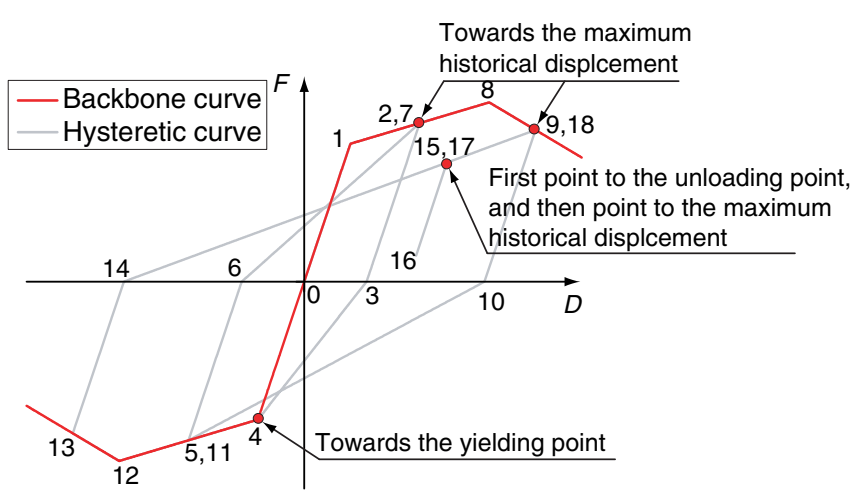

(b) Basic hysteretic rule

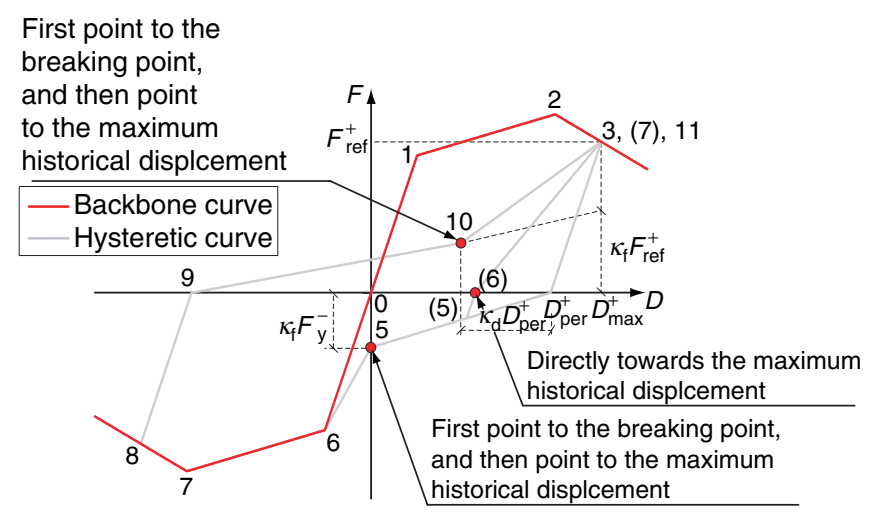

(c) Simulation of the pinching property

Figure 1. Description of the hysteretic model

The pinching property is modeled in Figure 1(c), which is described in detail by Ibarra et al. (2005). The pinching property is characterized by two parameters, $\kappa_{\mathrm{d}}$ and $\kappa_{\mathrm{f}}$, both of which have values that range between 0 and 1. Smaller values of $\kappa_{\mathrm{d}}$ and $\kappa_{\mathrm{f}}$ indicate a more serious pinching of the hysteretic loop.

The cyclic deterioration rule is based on the hysteretic energy dissipation model proposed by Rahnama and Krawinkler (1993), which has four cyclic deterioration modes, including basic strength, postcapping strength, unloading stiffness and accelerated reloading stiffness deteriorations (Ibarra et al. 2005). The parameters $\gamma_{b}, \gamma_{c}, \gamma_{k}, \gamma_{a}$, that correspond to these four deterioration modes, are set to be $\gamma, \gamma, 2 \gamma, \gamma$, respectively. In controlling the deterioration rate, the parameter $c$ is constantly set to be 1.0 for the purpose of reducing the number of parameters (Ibarra et al. 2005). The parameter $\gamma$ is a normalized index that measures the energy dissipation capacity of the structural system. The hysteretic curves with various $\gamma$ values are presented in Figure 2. As evident in the figure, the smaller the $\gamma$ value is, the more severe the cyclic deterioration would be.

In sidesway collapse, the gravity potential energy is gradually released as the structure responds horizontally and the gravity load is taken into account by the $P-\Delta$ effect. The $P-\Delta$ effect is incorporated by introducing a parallel linear elastic spring with a negative stiffness to the original hysteretic model (Bernal 1987; Asimakopoulos et al. 2007). The stiffness of the elastic spring is defined by $-\theta K_{\mathrm{e}}$ (Figure 3), where $\theta$ is the stability coefficient.

\section{THE CONCEPT OF COLLAPSE CAPACITY SPECTRUM}

\subsection{Collapse Capacity Assessment}

The seismic collapse capacity of SDOF systems is quantitatively evaluated by conducting IDAs. For a typical SDOF system, the IDA (Vamvatsikos and Cornell 2002, 2004) involves applying a set of earthquake ground motions to the structural system, incrementally scaling each ground motion to multiple levels of intensity and implementing nonlinear timehistory analysis until dynamic instability occurs. The 22 far-field records suggested in FEMA P695 (2009), containing an aggregate of 44 horizontal ground motion components, are adopted in this study as the representative ground motion set. This ground motion set has been carefully selected, to provide a rational representation of the random nature of strong earthquakes that may cause structural collapse. Such a ground motion selection also aims to maintain its generality by avoiding potential event-based bias, specific spectrum matching and soil-structurefoundation interaction. Detailed discussions on the ground motion set are provided in FEMA P695 (2009).

Figure 4(a) shows a typical IDA result of a SDOF system, which is also referred to as the 'dynamic pushover curve', on which each point is derived from a nonlinear time-history analysis and each curve represents the structural response from elasticity to yielding and finally to collapse when subjected to one incrementally scaled ground motion. The horizontal axis in the 'dynamic pushover curve' [Figure 4(a)] represents the engineering demand parameter $(E D P)$, hereafter 


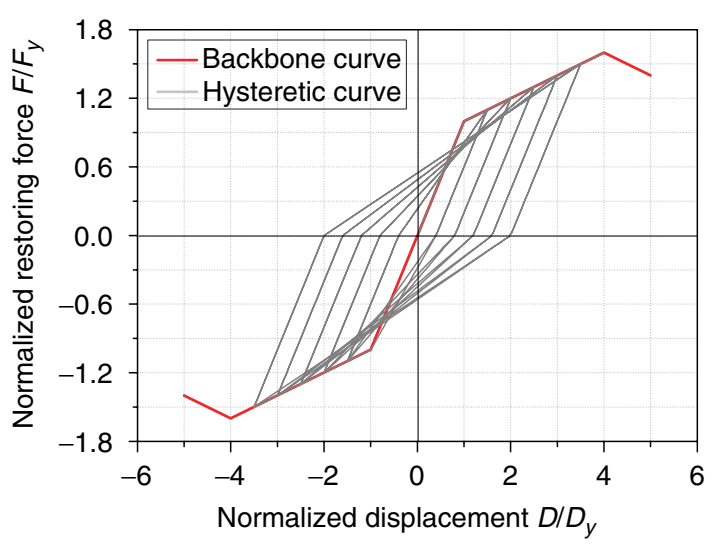

(a) $\gamma=+\infty$

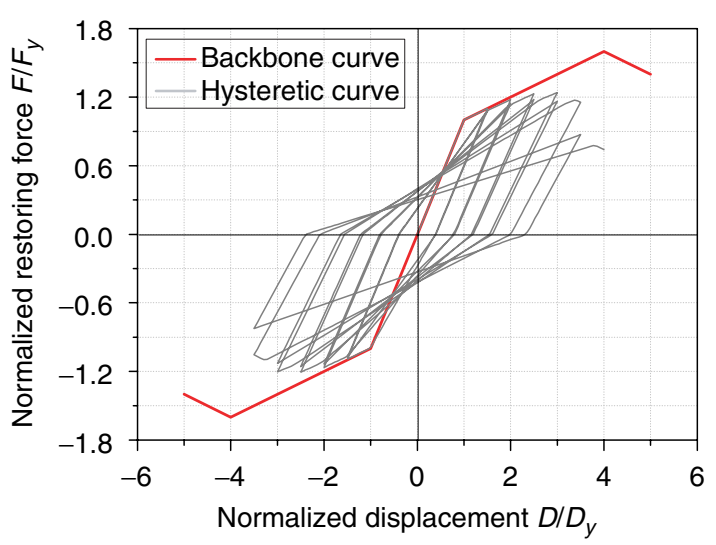

(c) $\gamma=100$

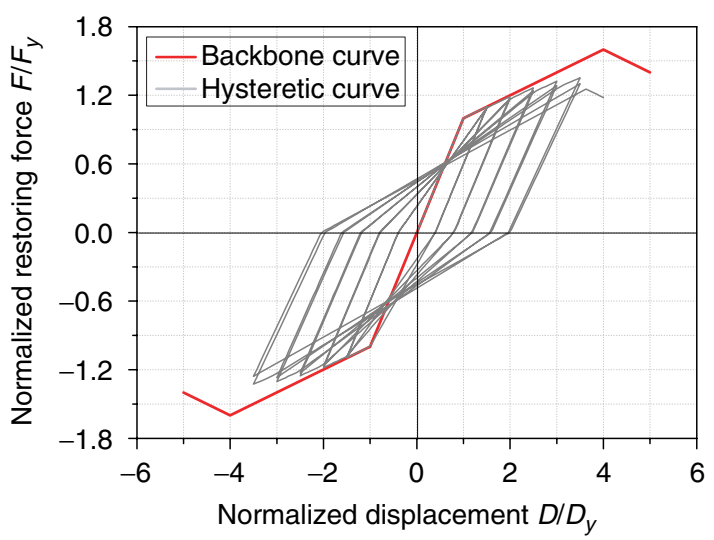

(b) $\gamma=100$

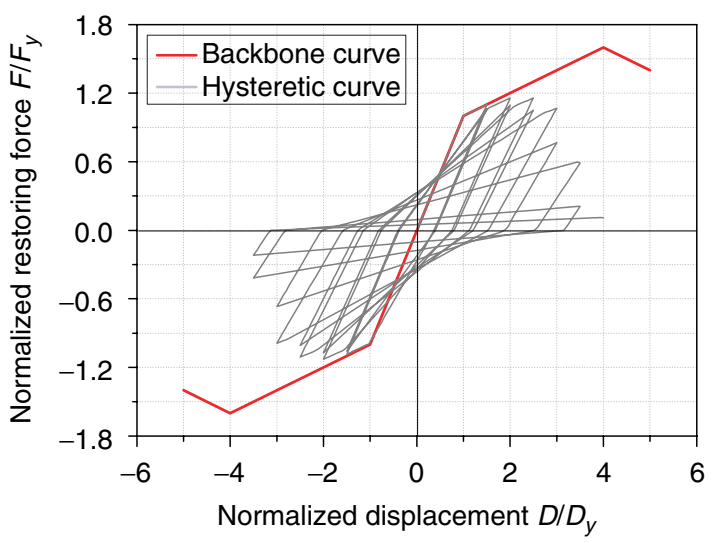

(b) $\gamma=25$

Figure 2. Hysteretic curves for various $\gamma$ values
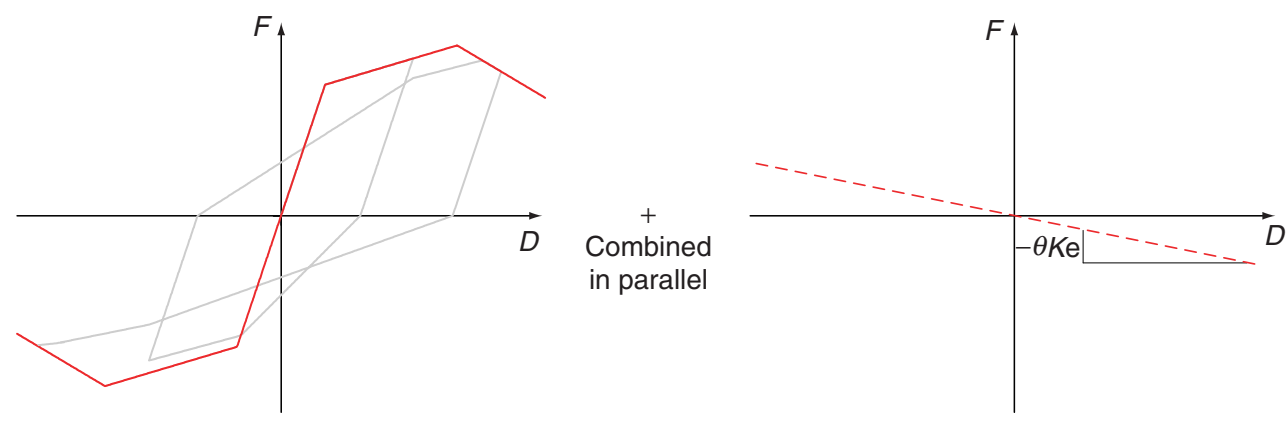

Figure 3. Simulation of the $P-\Delta$ effect

defined as the maximum displacement response obtained from the nonlinear time-history analysis and normalized by the yield displacement (see Eqn 1); the vertical axis is the intensity measure (IM) of ground motions. Note that the spectral acceleration at the fundamental period, $S_{\mathrm{a}}\left(T_{1}\right)$, is an effective and simple intensity measure (Ye et al. 2013). Based on $S_{\mathrm{a}}\left(T_{1}\right)$, a non-dimensional intensity measure is therefore proposed as defined in Eqn 2, where $M$ denotes the effective vibration mass of SDOF systems; $S_{\mathrm{a}}\left(T_{1}\right)_{5 \% \text { Damped }}$ is the $5 \%$ damped spectral acceleration at the fundamental period. Figure 4(a) also demonstrates that the initial tangents of the dynamic pushover curves derived from different ground motion inputs coincide with each other, because the horizontal and vertical axes are both properly normalized.

$$
E D P=\frac{|D|_{\max }}{D_{y}}
$$




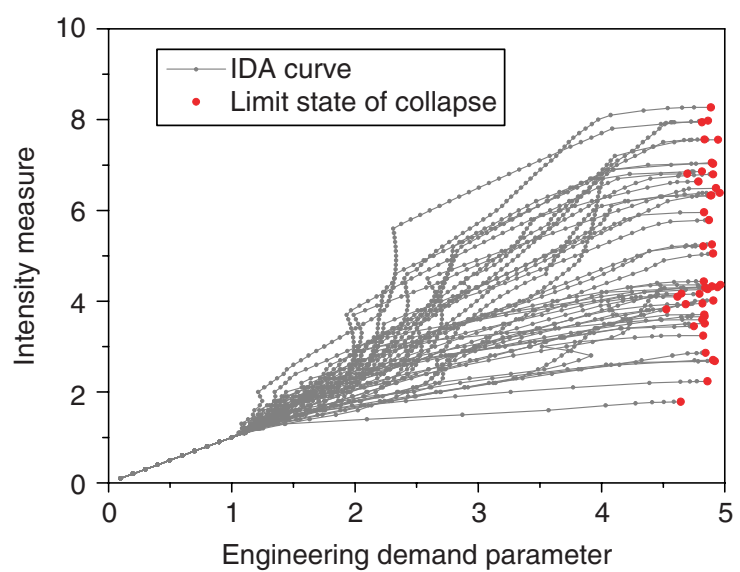

(a) Dynamic pushover curve

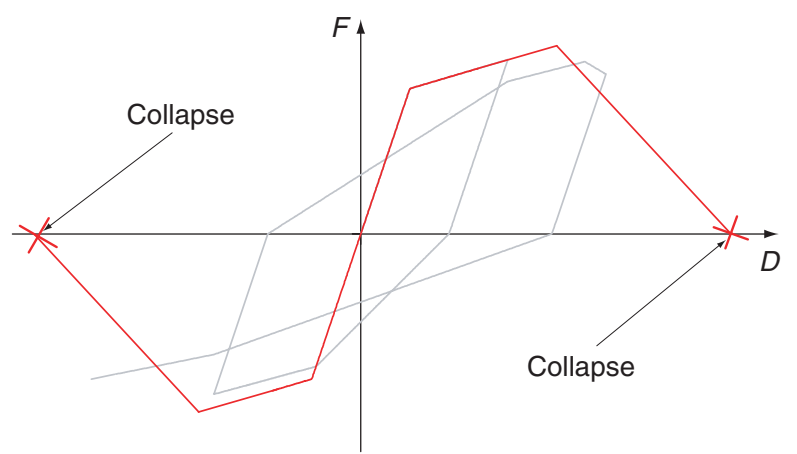

(b) Dynamic instability

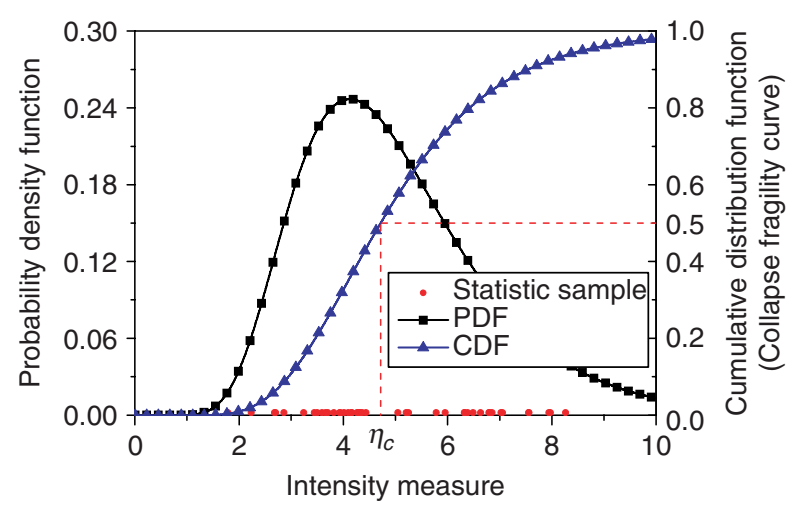

(c) Distribution of collapse capacity

Figure 4. Collapse capacity assessment of SDOF systems

$$
I M=\frac{M \times S a\left(T_{1}\right)_{5 \% \text { Damped }}}{K_{\mathrm{e}} \times D_{y}}
$$

In an IDA, the nonlinear time-history analysis of the structure subjected to an incrementally scaled ground motion is repeated until the structure reaches the collapse state when the ground motion is scaled up to the intensity level of $I M_{\text {Threshold }}$. The ultimate state of collapse is identified when the SDOF system completely loses its shear resistance [Figure 4(b)] (Araki and Hjelmstad 2000). The $I M_{\text {Threshold }}$ is the maximum ground motion intensity that the structure is able to resist before collapse and therefore is adopted as the metric quantifying the seismic collapse capacity of the structure subjected to this specific ground motion. For a given structure, various ground motions produce various $I M_{\text {Threshold }}$ values due to the variability in ground motions, i.e. the record-to-record (RTR) uncertainty (Kiureghian and Ditlevsen 2009). By assuming a logarithmic distribution, the seismic collapse resistance of the SDOF system is expressed in a mathematical form by $N\left(\operatorname{Ln}\left(\eta_{\mathrm{C}}\right), \beta_{\mathrm{RC}}\right)$, where $\eta_{\mathrm{C}}$ denotes the median value of the collapse resistance of the system and $\beta_{\mathrm{RC}}$ denotes the dispersion due to RTR uncertainty. Figure 4(c) displays the cumulative distribution function and probability density function of the collapse capacity of a typical SDOF system.

\subsection{Influence of Fundamental Period}

A tentative study has led to the recognition of a strong correlation between the collapse capacity of SDOF systems and their fundamental period of vibration. A flexible structural system (i.e., one with a longer period of vibration) tends to have a higher capacity to resist earthquake-induced collapse.

Figures 5 (a) to (d) display the dynamic pushover curves for four SDOF systems with fundamental periods of $0.2 \mathrm{~s}, 2.0 \mathrm{~s}, 4.0 \mathrm{~s}$ and $6.0 \mathrm{~s}$, respectively. All of the four SDOF systems have identical modeling parameters except for the elastic stiffness. It is observed from Figure 5 that the $E D P_{\text {Threshold values (i.e., the } E D P \text { that }}$ corresponds to the $I M_{\text {Threshold }}$ when the structure approaches collapse) of the flexible SDOF systems are slightly larger than those of the stiffer ones (e.g., from approximate 4.5 when $T_{1}=0.2 \mathrm{~s}$ to nearly 5.0 when $T_{1}$ $=6.0 \mathrm{~s}$ ). However, for the SDOF systems with larger fundamental period to reach $E D P_{\text {Threshold }}$, much stronger ground motions (i.e., larger $I M_{\text {Threshold }}$ ) are required. During the initial stages of earthquake engineering research, the 'equal displacement' and 'equal energy' rules (Riddell 2008) were discovered, which related the maximum deformation of an elasto-plastic system to the maximum deformation of the corresponding elastic system whose vibration period is the same as the inelastic system. For SDOF systems with larger fundamental period, the maximum deformation increases approximately linearly as the intensity of ground motion is increased because of the 'equal displacement' rule; whereas for SDOF systems with smaller fundamental period, the maximum deformation increases more rapidly than that for the flexible systems 


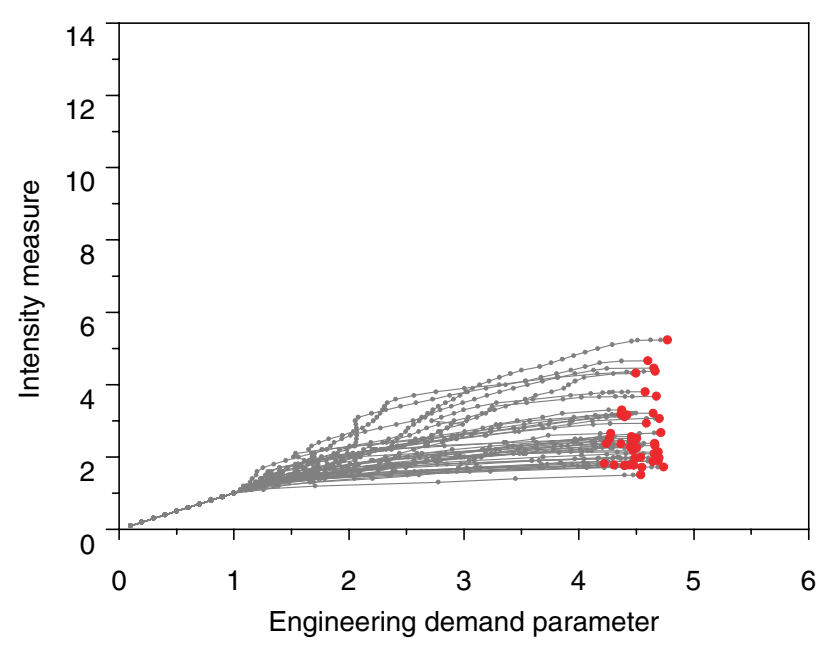

(a) $T_{1}=0.2 \mathrm{~s}$

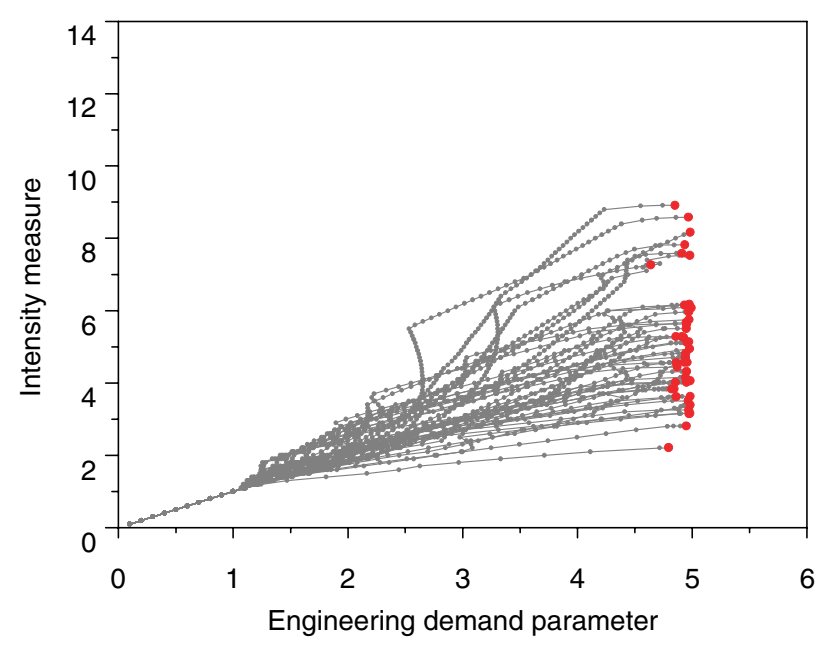

(c) $T_{1}=4.0 \mathrm{~s}$

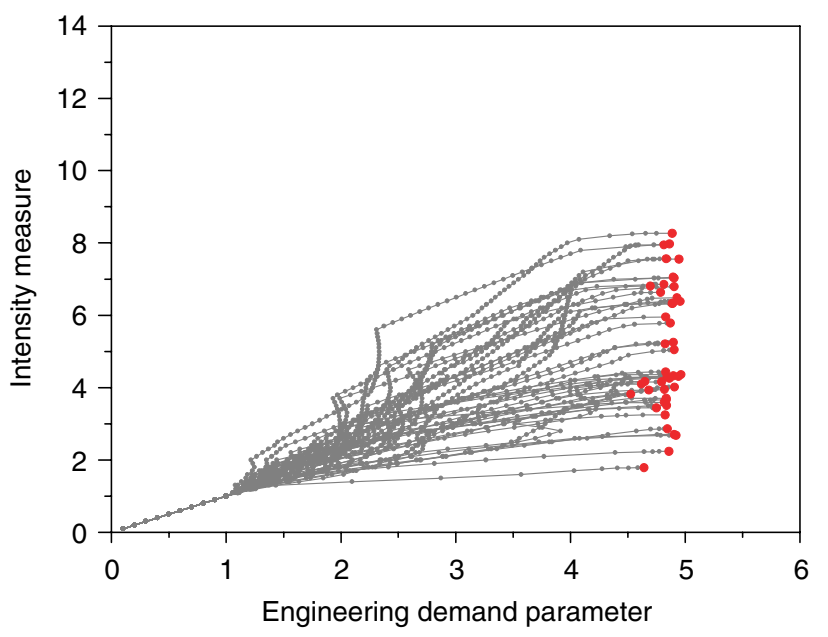

(b) $\mathrm{T}_{1}=2.0 \mathrm{~s}$

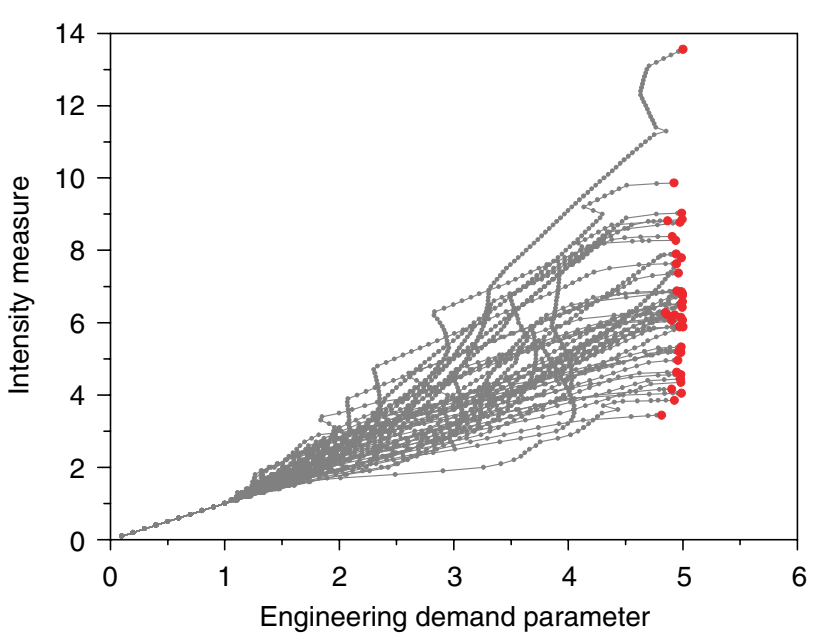

(d) $T_{1}=6.0 \mathrm{~s}$

Figure 5. Dynamic pushover curves for SDOF systems with various fundamental periods

as the intensity of ground motion is increased, due to the 'equal energy' rule. Therefore, flexible SDOF systems require stronger ground motion inputs to reach their $E D P_{\text {Threshold, }}$ which leads to a higher collapse resistance.

\subsection{Collapse Capacity Spectrum}

Because of the fact that the collapse capacity of SDOF systems is strongly correlated with its fundamental period of vibration, the median value and dispersion of the collapse capacity corresponding to the fundamental period of interest are quantified by carrying out IDAs on SDOF systems (Figure 6), which is defined as the collapse capacity spectrum. This spectrum is a rational extension of the classical inelastic response spectrum (Riddell 2008; Chopra 2001), which is used to study the strength demand of SDOF systems with given ductility capacity for various periods of vibration (Chakraborti and Gupta 2005), or the ductility demand of SDOF systems with given strength capacity (Miranda and Ruiz-Garcia 2002). Under both conditions, SDOF systems are limited in the nonlinear range without

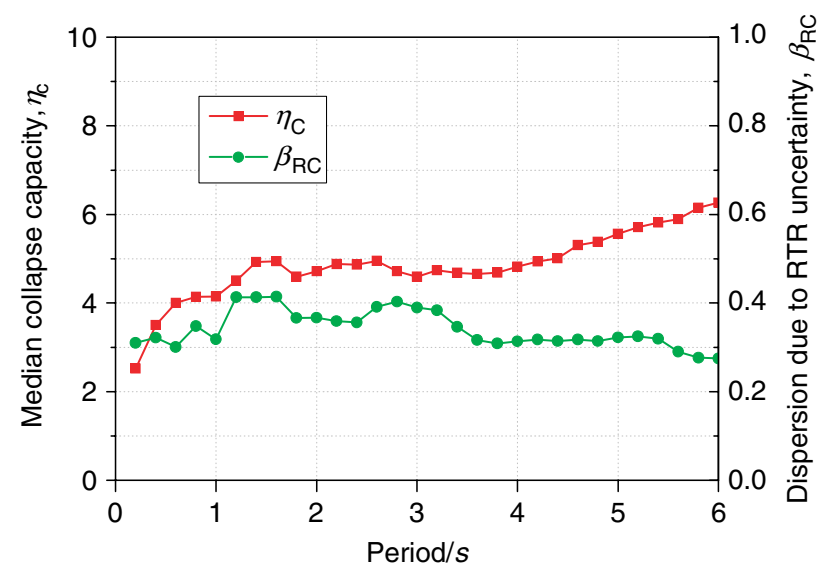

Figure 6. Collapse capacity spectrum 
excessive strength and stiffness deterioration (Krawinkler and Zareian 2007), and consequently the collapse state is not considered in the classical inelastic spectrum. In contrast, the collapse capacity spectrum focuses more on the ultimate state of collapse, which advances the investigation technique for collapse resistance of building structures.

As will be discussed in the following two sections, (i) a comprehensive parametric analysis of collapse capacity spectrum will offer insight into the collapse mechanism of SDOF systems and (ii) the collapse capacity spectrum can be used to study the engineering characteristics of earthquake ground motions, similar to the elastic response spectrum. Additionally, the collapse capacity spectrum has the potential to facilitate the static pushover-based approximate procedure to quantify the collapse resistance of MDOF systems, as stated in the opening section, and also to provide a reference for seismic design purposes. The collapse capacity spectrum uses the elastic strength demand normalized by the yield strength of the structure to measure the collapse capacity, which has a similar significance to the strength reduction factor from the perspective of seismic designs. According to the 2003 NEHRP provisions (FEMA 2004), a reduction factor $2 / 3$ is multiplied to the maximum considered earthquake (MCE) intensity to derive the design earthquake intensity. This reduction factor of $2 / 3$ is the reciprocal of a lower bound estimate of the inherent safety margin against collapse of the structures that are designed following the NEHRP provisions (Luco et al. 2007; FEMA 2004). The collapse capacity spectrum proposed in this study will be helpful to provide a direct analytical basis for calibrating such a reduction factor.

\section{PARAMETRIC STUDY OF COLLAPSE CAPACITY SPECTRUM}

This section discusses the influences of several major structural properties on the collapse capacity spectrum through a series of parametric analysis, including the ductility ratio, post-capping stiffness, hysteretic pinching, cyclic deterioration and the $P-\Delta$ effect. The analysis is performed using an in-house program developed by the authors which has been carefully validated through comparison with the analysis results generated from the general-purpose finite element software MSC.MARC. All the models used for the parametric analysis and their corresponding parameters are listed in Table 1. Amongst the models to be investigated, Model 1 is chosen as the benchmark model that provides a baseline against which the collapse capacity of SDOF systems with various structural properties is compared. When discussing a certain structural property (e.g., the ductility ratio), only the parameters that related to the property concerned are varied relative to the benchmark model (i.e., Model 1), so as to clearly demonstrate the influence of this property.

\subsection{Influence of Ductility Ratio}

In this study, the ductility ratio is defined as the ratio of the capping deformation to the yield deformation [Figure 1(a)]. The collapse capacity spectra of the SDOF systems with various ductility ratios (Models 1 and 2-5) are shown in Figure 7. It is observed from Figure 7(a) that (i) structural systems with larger ductility ratios have much higher collapse resistance; (ii) the ductility also affects the pattern of the collapse capacity spectrum, which may be less obvious. For the SDOF systems with smaller ductility ratios, (e.g., $\mu=$ 2.0 and $\mu=3.0$ ), the collapse capacity spectrum increases abruptly within the acceleration-sensitive range and reaches a plateau within the velocity-sensitive range. For the SDOF systems with larger ductility ratios (e.g., $\mu=5.0$ and $\mu=6.0$ ), the collapse capacity spectrum reaches another plateau within the displacement-sensitive range if the period elongation owing to yielding is considered (Mehanny 1999), whereas this phenomenon is not observed for those nonductile SDOF systems.

It is interesting to note that when analyzing the dispersion of collapse capacity spectrum [Figure 7(b)], SDOF systems with larger ductility ratios will systematically have larger dispersion, indicating that the SDOF systems with larger ductility ratios are more sensitive to the RTR uncertainty.

\subsection{Influence of Post-Capping Stiffness}

The post-capping stiffness is governed by the softening ratio $\alpha_{\mathrm{c}}$, which is defined as the absolute ratio of the stiffness of post-capping branch to the elastic stiffness [Figure 1(a)]. A larger $\alpha_{\mathrm{c}}$ value indicates a steeper slope of the post-capping branch. The collapse capacity spectra of the SDOF systems with various softening ratios (Models 1 and 6-10) are shown in Figure 8. The influence of the post-capping stiffness on the collapse capacity spectrum is generally insignificant compared to the influence of the ductility ratio. When the softening ratio $\alpha_{\mathrm{c}}$ is greater than 1.0 , its influence is negligible. However, when the softening ratio $\alpha_{\mathrm{c}}$ is smaller than 1.0, the SDOF systems with a gentle post-capping slope have higher collapse capacity, especially for those flexible structures.

\subsection{Influence of Hysteretic Pinching Behavior}

The hysteretic pinching behavior is controlled by two parameters $\kappa_{\mathrm{f}}$ and $\kappa_{\mathrm{d}}$ [Figure 1(c)]. The combination of different $\kappa_{\mathrm{f}}$ and $\kappa_{\mathrm{d}}$ values covers a wide range of 
Table 1. Model identifier and modeling parameters

\begin{tabular}{|c|c|c|c|c|c|c|c|}
\hline Model ID & $\alpha_{\mathbf{s}}$ & $\mu$ & $\alpha_{\mathbf{c}}$ & $\kappa_{\mathbf{f}}$ & $\kappa_{\mathbf{d}}$ & $\gamma$ & $\theta$ \\
\hline Model 1 (benchmark) & 0.0 & 4.0 & 1.0 & \multicolumn{2}{|c|}{ No Pinching } & Infinity & 0.00 \\
\hline Model 2 & 0.0 & 2.0 & 1.0 & \multicolumn{2}{|c|}{ No Pinching } & Infinity & 0.00 \\
\hline Model 3 & 0.0 & 3.0 & 1.0 & \multicolumn{2}{|c|}{ No Pinching } & Infinity & 0.00 \\
\hline Model 4 & 0.0 & 5.0 & 1.0 & \multicolumn{2}{|c|}{ No Pinching } & Infinity & 0.00 \\
\hline Model 5 & 0.0 & 6.0 & 1.0 & \multicolumn{2}{|c|}{ No Pinching } & Infinity & 0.00 \\
\hline Model 6 & 0.0 & 4.0 & 0.5 & \multicolumn{2}{|c|}{ No Pinching } & Infinity & 0.00 \\
\hline Model 7 & 0.0 & 4.0 & 1.5 & \multicolumn{2}{|c|}{ No Pinching } & Infinity & 0.00 \\
\hline Model 8 & 0.0 & 4.0 & 2.0 & \multicolumn{2}{|c|}{ No Pinching } & Infinity & 0.00 \\
\hline Model 9 & 0.0 & 4.0 & 2.5 & \multicolumn{2}{|c|}{ No Pinching } & Infinity & 0.00 \\
\hline Model 10 & 0.0 & 4.0 & 3.0 & \multicolumn{2}{|c|}{ No Pinching } & Infinity & 0.00 \\
\hline Model 11 & 0.0 & 4.0 & 1.0 & 0.8 & 1.0 & Infinity & 0.00 \\
\hline Model 12 & 0.0 & 4.0 & 1.0 & \multicolumn{2}{|r|}{1.0} & Infinity & 0.00 \\
\hline Model 13 & 0.0 & 4.0 & 1.0 & \multicolumn{2}{|l|}{0.4} & Infinity & 0.00 \\
\hline Model 14 & 0.0 & 4.0 & 1.0 & \multicolumn{2}{|l|}{0.2} & Infinity & 0.00 \\
\hline Model 15 & 0.0 & 4.0 & 1.0 & \multicolumn{2}{|l|}{0.8} & Infinity & 0.00 \\
\hline Model 16 & 0.0 & 4.0 & 1.0 & \multicolumn{2}{|l|}{0.6} & Infinity & 0.00 \\
\hline Model 17 & 0.0 & 4.0 & 1.0 & \multicolumn{2}{|l|}{0.4} & Infinity & 0.00 \\
\hline Model 18 & 0.0 & 4.0 & 1.0 & \multicolumn{2}{|l|}{0.2} & Infinity & 0.00 \\
\hline Model 19 & 0.0 & 4.0 & 1.0 & \multicolumn{2}{|l|}{0.8} & Infinity & 0.00 \\
\hline Model 20 & 0.0 & 4.0 & 1.0 & \multicolumn{2}{|l|}{0.6} & Infinity & 0.00 \\
\hline Model 21 & 0.0 & 4.0 & 1.0 & \multicolumn{2}{|l|}{0.4} & Infinity & 0.00 \\
\hline Model 22 & 0.0 & 4.0 & 1.0 & \multirow{2}{*}{\multicolumn{2}{|c|}{$\begin{array}{l}0.2 \text { No Pinching } \\
{ }^{0.0}\end{array}$}} & Infinity & 0.00 \\
\hline Model 23 & 0.0 & 4.0 & 1.0 & & & 500 & 0.00 \\
\hline Model 24 & 0.0 & 4.0 & 1.0 & \multicolumn{2}{|c|}{ No Pinching } & 300 & 0.00 \\
\hline Model 25 & 0.0 & 4.0 & 1.0 & \multicolumn{2}{|c|}{ No Pinching } & 100 & 0.00 \\
\hline Model 26 & 0.0 & 4.0 & 1.0 & & & 50 & 0.00 \\
\hline Model 27 & 0.0 & 4.0 & 1.0 & & & 25 & 0.00 \\
\hline Model 28 & 0.0 & 2.0 & 1.0 & & & Infinity & 0.00 \\
\hline Model 29 & 0.0 & 2.0 & 1.0 & & & 500 & 0.00 \\
\hline Model 30 & 0.0 & 2.0 & 1.0 & & & 300 & 0.00 \\
\hline Model 31 & 0.0 & 2.0 & 1.0 & & & 100 & 0.00 \\
\hline Model 32 & 0.0 & 2.0 & 1.0 & & & 50 & 0.00 \\
\hline Model 33 & 0.0 & 2.0 & 1.0 & & & 25 & 0.00 \\
\hline Model 34 & 0.0 & 6.0 & 1.0 & & & Infinity & 0.00 \\
\hline Model 35 & 0.0 & 6.0 & 1.0 & & & 500 & 0.00 \\
\hline Model 36 & 0.0 & 6.0 & 1.0 & & & 300 & 0.00 \\
\hline Model 37 & 0.0 & 6.0 & 1.0 & & & 100 & 0.00 \\
\hline Model 38 & 0.0 & 6.0 & 1.0 & & & 50 & 0.00 \\
\hline Model 39 & 0.0 & 6.0 & 1.0 & & & 25 & 0.00 \\
\hline Model 40 & 0.0 & 4.0 & 1.0 & & & Infinity & 0.04 \\
\hline Model 41 & 0.0 & 4.0 & 1.0 & & & Infinity & 0.08 \\
\hline Model 42 & 0.0 & 4.0 & 1.0 & & & Infinity & 0.12 \\
\hline Model 43 & 0.0 & 4.0 & 1.0 & & & Infinity & 0.16 \\
\hline
\end{tabular}

pinching degrees of the hysteretic loops. The collapse capacity spectra of the SDOF systems with various pinching properties (Models 1 and 11-22) are shown in Figure 9.

Traditionally, structures with less pinching behaviors are considered to have better energy dissipation capacities, so they should be better able to resist collapse. However, a comparison of the collapse capacity spectra for the SDOF systems with various pinching properties reveals that the hysteretic pinching behavior generally has little effect on the collapse resistance of the SDOF system, neither on the median value nor on the dispersion. For Model 22, whose hysteretic pinching behavior is the most severe among the investigated cases, its collapse capacity spectrum is slightly lower during the short period range and almost the same during the median and long period ranges, relative to the collapse capacity spectrum of Model 1, which has no pinching effect. This outcome differs from the results based on traditional inelastic response spectrum available in existing literature, in which the hysteretic pinching behavior will amplify the ductility 


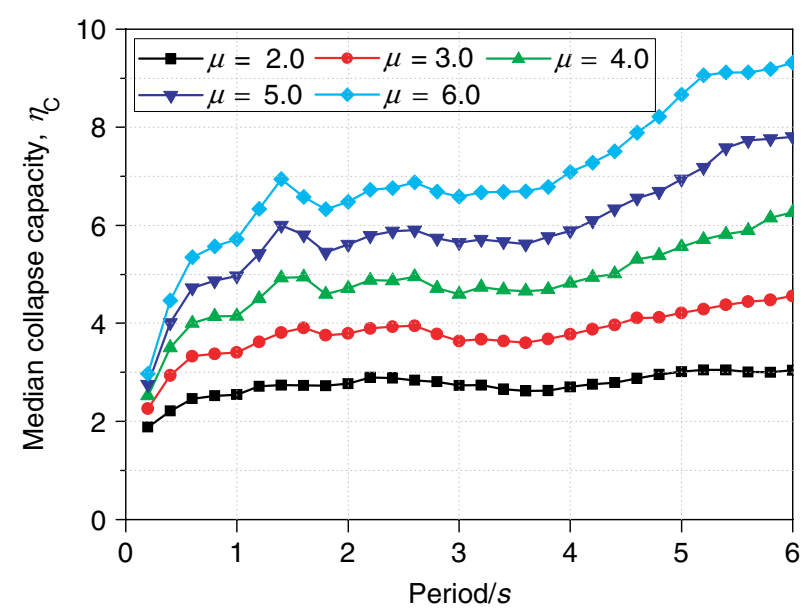

(a) Median collapse capacity

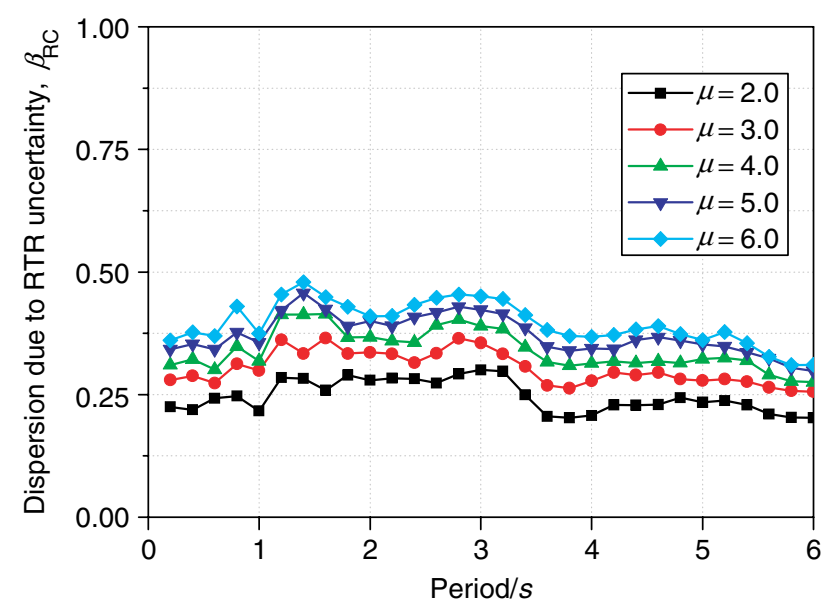

(b) Dispersion due to RTR uncertainty

Figure 7. Influence of the ductility ratio $\mu$ on collapse capacity spectrum $\left(\alpha_{\mathrm{s}}=0.00, \alpha_{\mathrm{c}}=1.0, \kappa_{\mathrm{f}}=1.0, \gamma=\right.$ Infinity, $\left.\theta=0.00\right)$

demand under given strength capacity (Lee et al. 1999). This difference between collapse capacity spectrum and the traditional inelastic response spectrum is attributed to whether the seismic action or the displacement response is concerned. Generating collapse capacity spectrum requires the SDOF systems to develop into the post-capping branch. Under such conditions, a subtle increase in the seismic action may result in a large increase in the earthquake response, i.e. the tail of the IDA curve is quite flat [see Figure 4(a)]. The collapse capacity spectrum focuses more on the seismic action that causes the structure collapse and hence the influence of hysteretic pinching property on the collapse capacity spectrum can be negligible. This finding can be supported by a published work on seismic force modification factors with given ductility capacities (e.g. Tong and Zhao 2007).

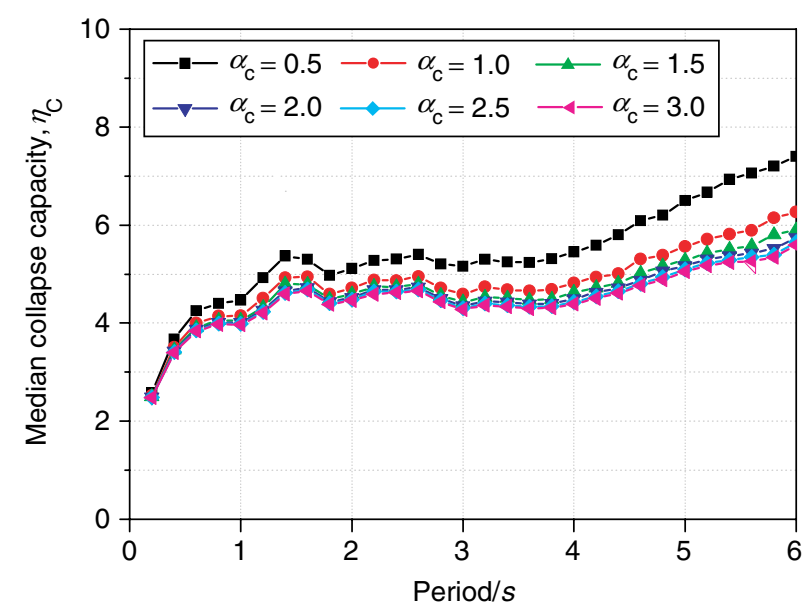

(a) Median collapse capacity

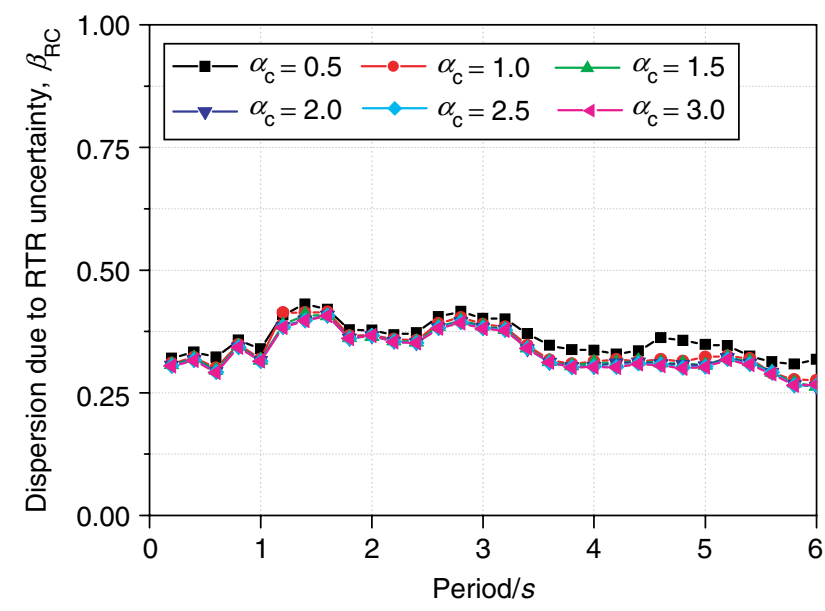

(b) Dispersion due to RTR uncertainty

Figure 8. Influence of the softening ratio $\alpha_{\mathrm{c}}$ on collapse capacity spectrum $\left(\alpha_{\mathrm{s}}=0.00, \mu=4.0, \kappa_{\mathrm{f}}=1.0, \gamma=\right.$ Infinity, $\left.\theta=0.00\right)$

\subsection{Influence of Cyclic Deterioration}

To reduce the number of parameters, the following four cyclic deterioration modes, including the basic strength, post-capping strength, unloading stiffness and accelerated reloading stiffness deteriorations, are considered simultaneously and controlled by the common parameter $\gamma$ in the investigated models (Figure 2). The collapse capacity spectra of the SDOF systems with various cyclic deterioration properties (Models 1 and 23-39), covering a wide range of deterioration degree from non-deterioration to severe deterioration cases, are shown in Figure 10.

The cyclic deterioration effect on the collapse capacity spectrum obviously interacts with the ductility capacity (Figure 10). For non-ductile systems (e.g., $\mu=$ 2.0 ), the collapse resistance is slightly degraded due to more severe cyclic deterioration [Figure 10(a)]; whereas for more ductile systems (e.g., $\mu=4.0$ and 

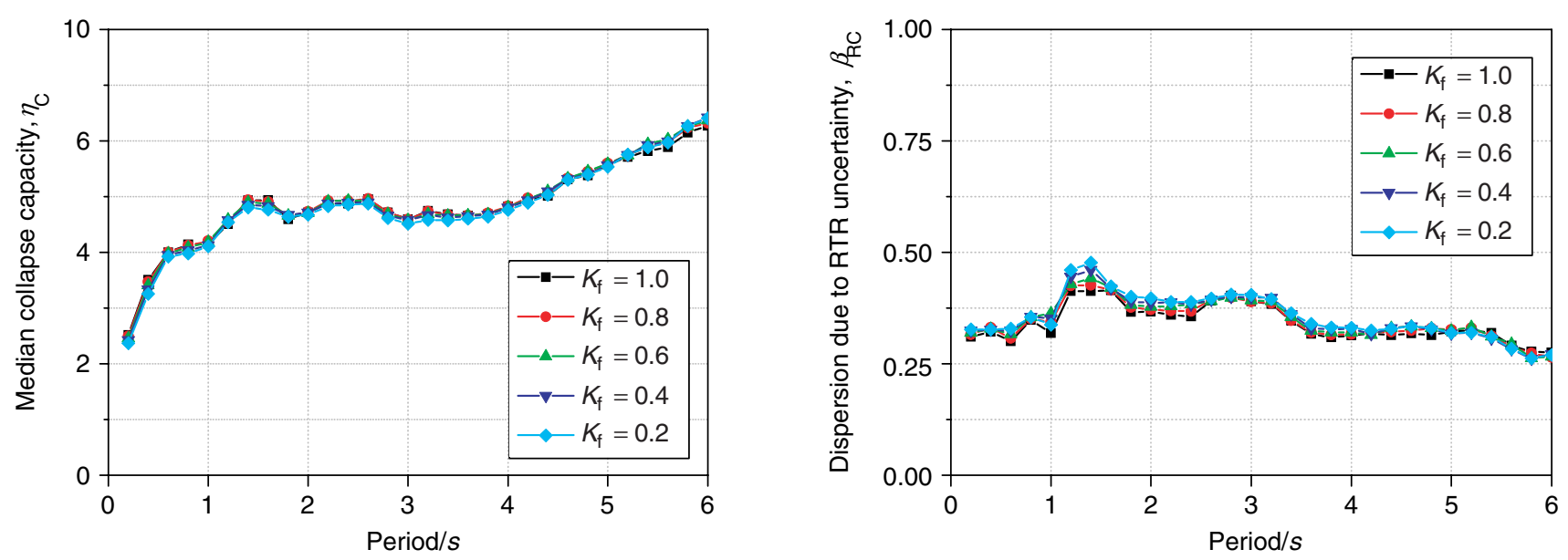

(a) $\kappa_{\mathrm{d}}=1.0$
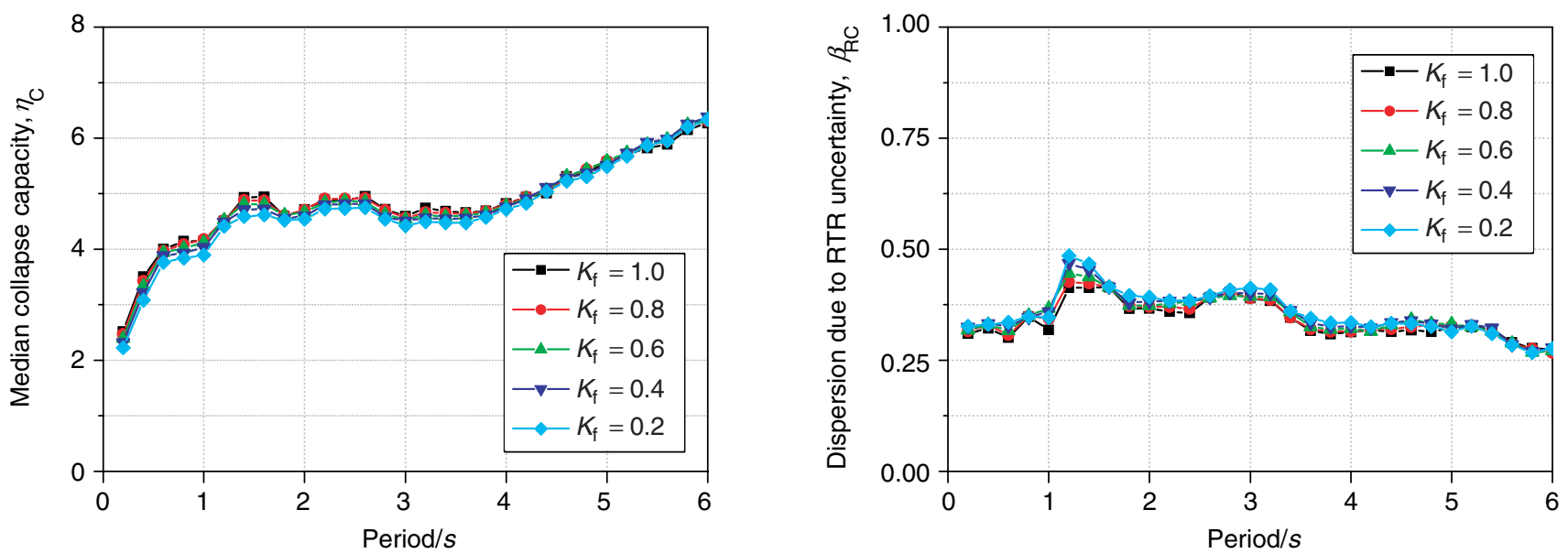

(b) $\kappa_{\mathrm{d}}=0.5$
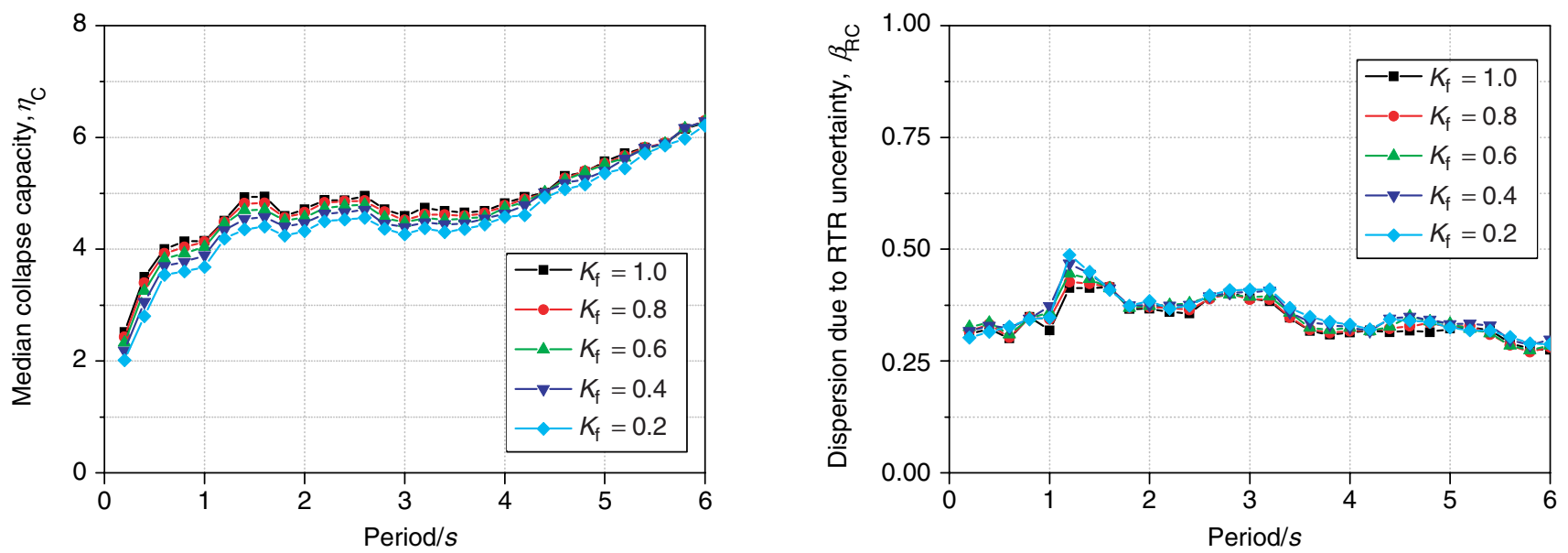

(c) $\kappa_{\mathrm{d}}=0.0$

Figure 9. Influence of the pinching property on collapse capacity spectrum $\left(\alpha_{\mathrm{s}}=0.00, \mu=4.0, \alpha_{\mathrm{c}}=1.0, \gamma=\right.$ Infinity, $\left.\theta=0.00\right)$

$\mu=6.0$ ), the deterioration effect significantly degrades the collapse resistance as cyclic deterioration becomes more severe [Figure 10(b) and (c)]. Furthermore, a smaller dispersion in the collapse resistance will be observed for SDOF systems with more severe cyclic deterioration. As stated in the discussion about the 

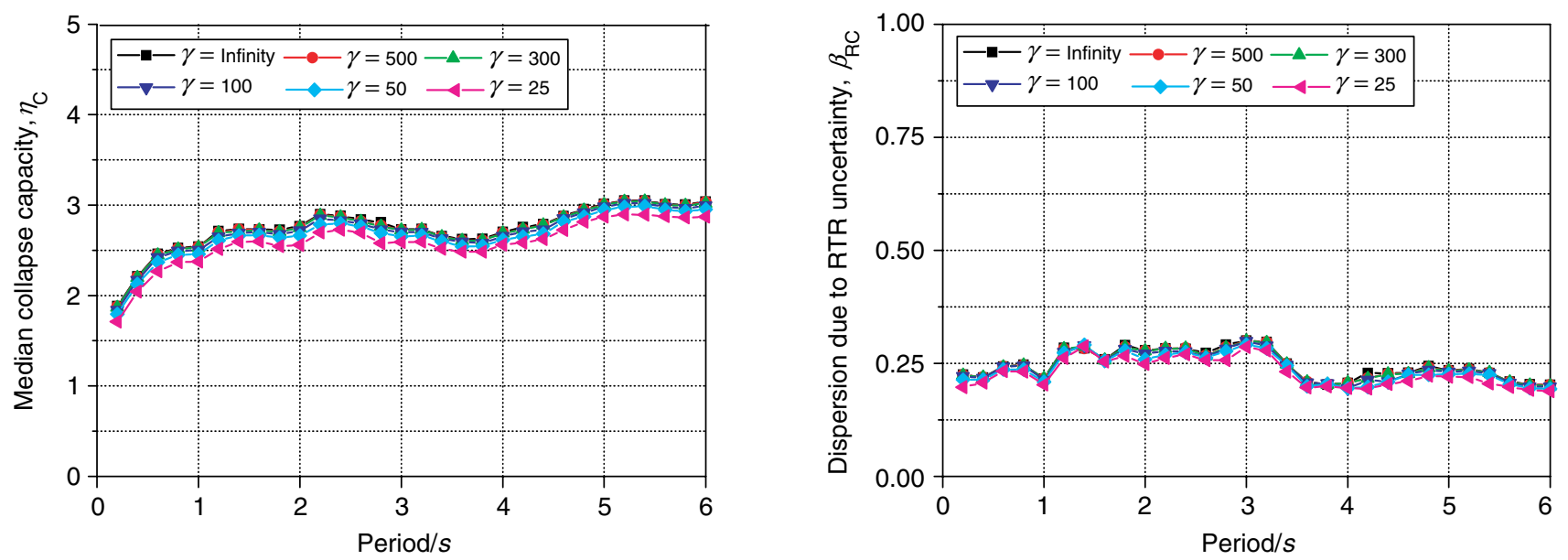

(a) $\mu=2.0$
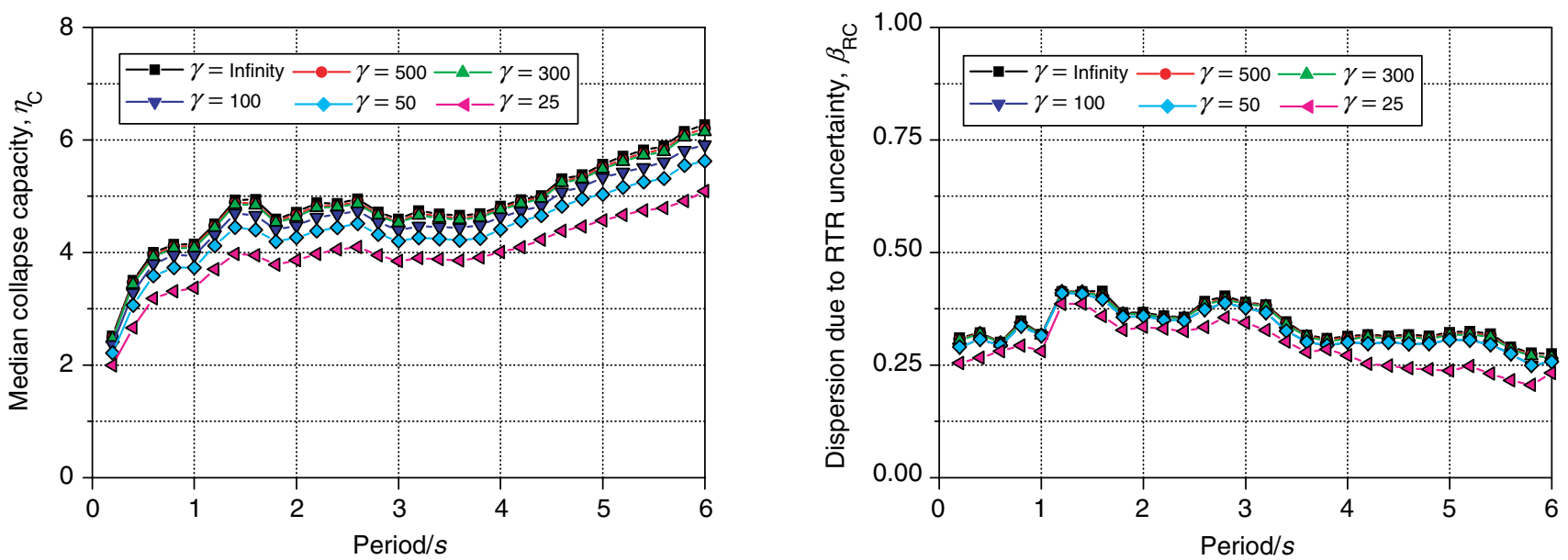

(b) $\mu=4.0$
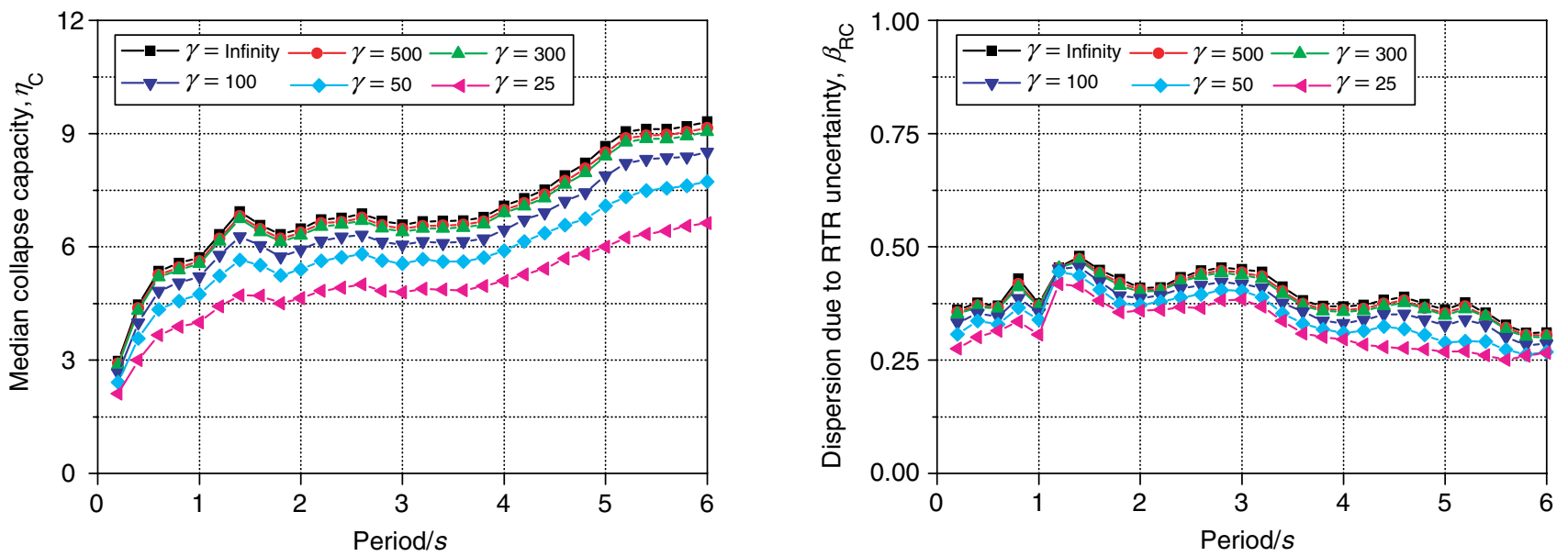

(c) $\mu=6.0$

Figure 10. Effect of the cyclic deterioration property on collapse capacity spectrum $\left(\alpha_{\mathrm{s}}=0.00, \alpha_{\mathrm{c}}=1.0, \kappa_{\mathrm{f}}=1.0, \theta=0.00\right)$

influence of the ductility ratio, the collapse resistance of the SDOF systems with lower ductility exhibits less dispersion due to RTR uncertainty. The cyclic deterioration reduces the structural ductility capacity, and the dispersion in the collapse resistance is reduced accordingly. 


\subsection{Influence of the $P-\Delta$ Effect}

The $P-\Delta$ effect is essentially induced by a release of the gravitational potential energy (Kato 2010) and it is modeled with the stability coefficient $\theta$ in this work (Figure 3 ). The $P-\Delta$ effect has both positive and negative influences on the structural responses under earthquake excitation. The positive effect is that the $P-\Delta$ effect reduces the structural stiffness and elongates the structural fundamental period. Structures with longer fundamental period will generally have a higher seismic collapse capacity. However, the $P$ - $\Delta$ effect amplifies the structural response, which then weakens the collapse resistance. Unfortunately, this adverse effect is dominant, which is apparent when evaluating the collapse capacity spectra of SDOF systems with various $\theta$ values (Models 1 and 40-43) in Figure 11. As evident in the figure, the median value decreases proportionally over the entire period range as $\theta$ values increase and the dispersion remains stable. This phenomenon agrees well
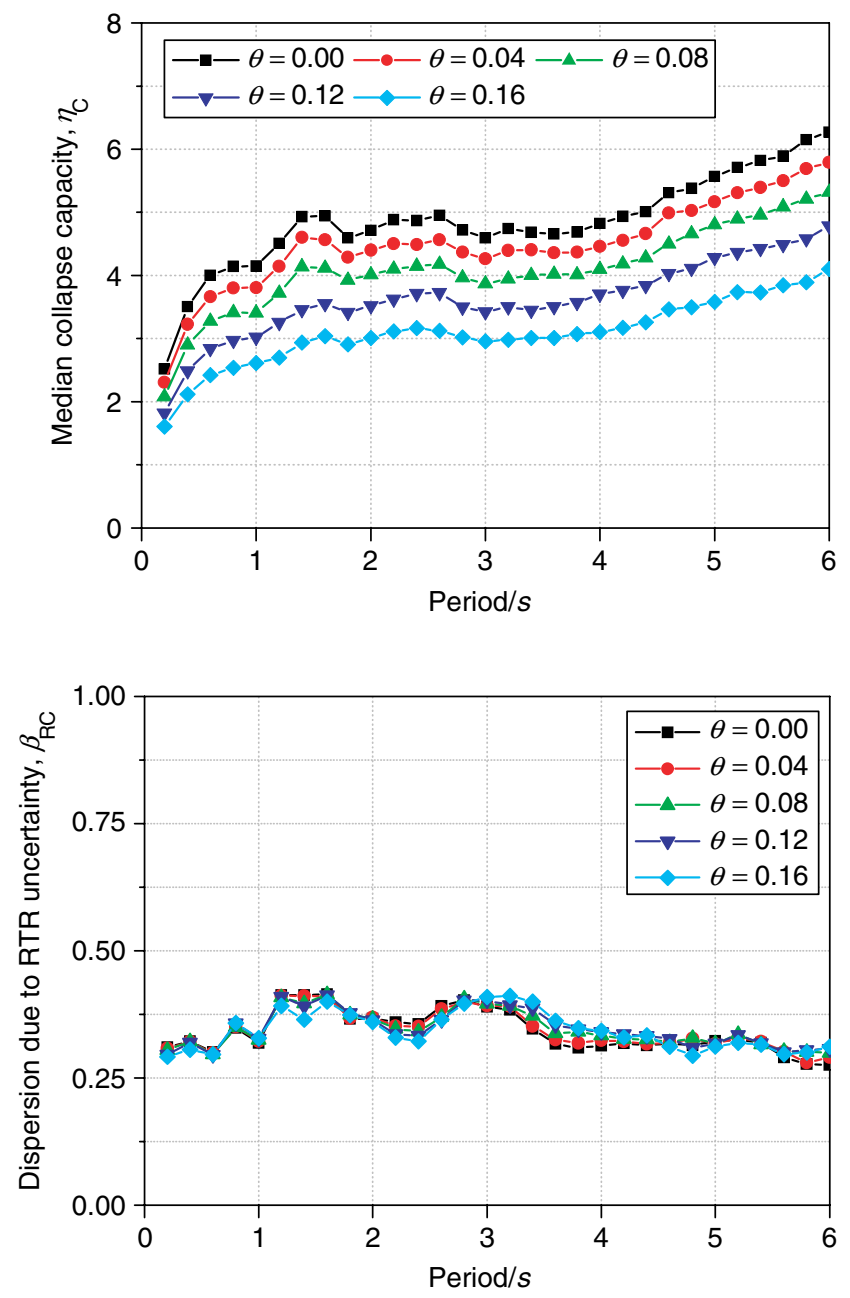

Figure 11. Effect of the $P-\Delta$ Effect on collapse capacity spectrum $\left(\alpha_{\mathrm{s}}=0.00, \mu=4.0, \alpha_{\mathrm{c}}=1.0, \kappa_{\mathrm{f}}=1.0, \gamma=\right.$ Infinity $)$ with a similar work based on the bilinear hysteretic models (Adam and Jäger 2012).

\section{ENGINEERING CHARACTERISTICS OF GROUND MOTIONS}

To investigate the potential influence of various ground motions, two additional ground motion record sets suggested by FEMA P695 (2009) are used as input for Model 1, and the corresponding collapse capacity spectra are calculated via IDA. The two sets of ground motions are both recorded on near-field sites with siteto-rupture distance being less than $10 \mathrm{~km}$, of which one set contains rupture directivity pulses (Malhotra 1999; Chopra and Chintanapakdee 2001) while the other set does not.

The collapse capacity spectra of Model 1 derived from various sets of ground motion records are shown in Figure 12. It is observed that structures with fundamental periods ranging from $0.4 \mathrm{~s}$ to $1.8 \mathrm{~s}$ are more vulnerable
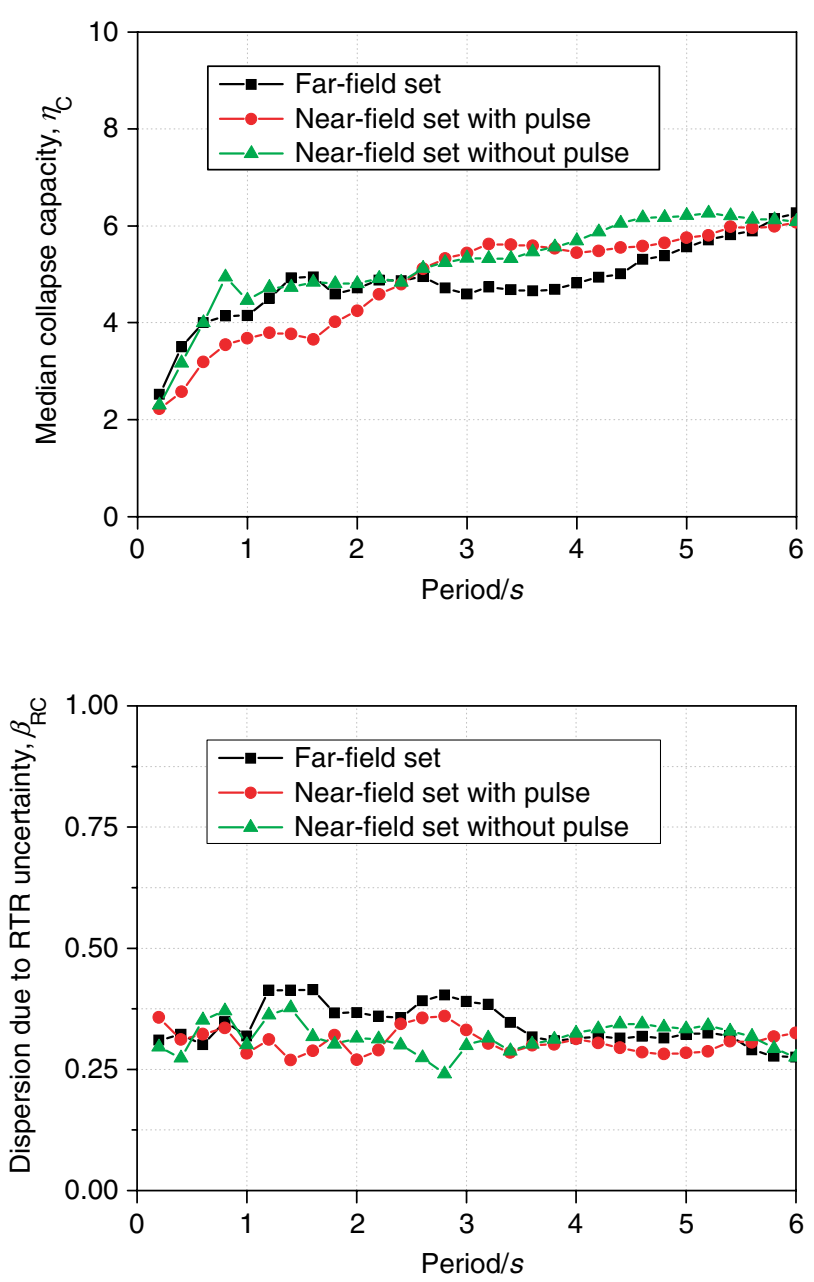

Figure 12. Collapse capacity spectrum with different ground motion input 
to the near-field pulse-like ground motions, which coincides with previous earthquake damage investigations and theoretical analysis by other researchers (Malhotra 1999; Champion and Liel 2012). Previous work had indicated that near-field ground motions containing directivity pulse generally impose higher ductility demand on structures with short-tomedian fundamental periods (Malhotra 1999; Chopra and Chintanapakdee 2001). The pattern of collapse capacity spectrum derived from the near-field pulse-like ground motions is still similar to the previous discussion. The collapse resistance increases abruptly within the acceleration-sensitive range and reaches a plateau within the velocity-sensitive range. The fact that near-field pulse-like ground motions have a wider accelerationsensitive range and narrower velocity-sensitive range explains the relatively low collapse capacity over the period range from $0.4 \mathrm{~s}$ to $1.8 \mathrm{~s}$ (Chopra and Chintanapakdee 2001). Additionally, the structures with fundamental periods ranging from $2.6 \mathrm{~s}$ to $5.0 \mathrm{~s}$ are more vulnerable to the far-field set relative to both near-field sets because the far-field ground motions generally contain more components with long period.

\section{SUMMARY AND CONCLUSIONS}

This paper utilizes the IDA-based collapse fragility evaluation approach to quantitatively assess the seismic capacity of SDOF systems to resist sidesway collapse and proposes the concept of collapse capacity spectrum, which is a rational extension of the classical inelastic response spectrum. The calculation procedure and engineering significance of the collapse capacity spectrum are illustrated. The collapse capacity spectrum provides a quantitative estimation for the collapse capacity of SDOF systems. This spectrum will be helpful to provide a direct analytical basis for collapse safety margin and also to facilitate the static pushoverbased approximate methods of collapse evaluation. Through a systematic parametric discussion on the collapse capacity spectrum, the major findings of this study are summarized below:

(i) Fundamental periods are important factors for the collapse capacity, and ductile structures generally have high collapse capacity but are more sensitive to RTR uncertainty. The influence of the post-capping stiffness on the collapse capacity spectrum is generally insignificant compared to that of the ductility ratio. When the softening ratio $\alpha_{\mathrm{c}}$ is greater than 1.0 , its influence is negligible.

(ii) The ductility capacity and $P-\Delta$ effect are important factors in collapse evaluation, whereas the pinching effect is essentially negligible in collapse evaluation. The cyclic deterioration effect depends on the structural ductility capacity, i.e. it is negligible for nonductile structures while it considerably degrades the collapse capacity for ductile structures.

(iii) The influence of earthquake ground motions on the collapse resistance capacity of SDOF systems depends on the fundamental period. Structures with fundamental periods ranging from $0.4 \mathrm{~s}$ to $1.8 \mathrm{~s}$ are more vulnerable to the near-field pulse-like ground motions and structures with fundamental periods ranging from $2.6 \mathrm{~s}$ to $5 \mathrm{~s}$ are more vulnerable to the far-field ones.

\section{ACKNOWLEDGEMENTS}

The authors are grateful for the financial support received from the National Key Technology R\&D Program (No. 2013BAJ08B02), and the National Nature Science Foundation of China (No. 51222804, 51178249, 51378299).

\section{REFERENCES}

Adam, C. and Jäger, C. (2012). "Seismic collapse capacity of basic inelastic structures vulnerable to the P-delta effect", Earthquake Engineering \& Structural Dynamics, Vol. 41, No. 4, pp. 775-793.

Araki, Y. and Hjelmstad, K.D. (2000). "Criteria for assessing dynamic collapse of elastoplastic structural systems", Earthquake Engineering \& Structural Dynamics, Vol. 29, No. 8, pp. 1177-1198.

Asimakopoulos, A.V., Karabalis, D.L. and Beskos, D.E. (2007). "Inclusion of $P-\Delta$ effect in displacement-based seismic design of steel moment resisting frames", Earthquake Engineering \& Structural Dynamics, Vol. 36, No. 14, pp. 2171-2188.

Bernal, D. (1987). "Amplification factors for inelastic dynamic $p-\Delta$ effects in earthquake analysis", Earthquake Engineering \& Structural Dynamics, Vol. 15, No. 5, pp. 635-651.

Bernal, D. (1992). "Instability of buildings subjected to earthquakes", Journal of Structural Engineering, ASCE, Vol. 118, No. 8, pp. 2239-2260.

Brookshire, D.S., Chang, S.E., Cochrane, H., Olson, R.A., Rose, A. and Steenson, J. (1997). "Direct and indirect economic losses from earthquake damage", Earthquake Spectra, Vol. 13, No. 4, pp. 683-701.

Chakraborti, A. and Gupta, V.K. (2005). "Scaling of strength reduction factors for degrading elasto-plastic oscillators", Earthquake Engineering \& Structural Dynamics, Vol. 34, No. 2, pp. 189-206.

Champion, C. and Liel, A. (2012). "The effect of near-fault directivity on building seismic collapse risk", Earthquake Engineering \& Structural Dynamics, Vol. 41, No. 10, pp. 1391-1409. 
Chopra, A.K. (2001). Dynamic of Structures-Theory and Applications to Earthquake Engineering, Prentice Hall, New Jersey, USA.

Chopra, A.K. and Chintanapakdee, C. (2001). "Comparing response of SDF systems to near-fault and far-fault earthquake motions in the context of spectral regions", Earthquake Engineering \& Structural Dynamics, Vol. 30, No. 12, pp. 1769-1789.

Clough, R.W. and Johnston, S.B. (1966). "Effect of stiffness degradation on earthquake ductility requirements", Proceedings of Japan Earthquake Engineering Symposium, Tokyo, Japan.

DesRoches, R., Comerio, M., Eberhard, M., Mooney, W. and Rix, G.J. (2011). "Overview of the 2010 Haiti earthquake", Earthquake Spectra, Vol. 27, No. S1, pp. 1-21.

Fajfar, P. and Dolšek, M. (2011). "A practice-oriented estimation of the failure probability of building structures", Earthquake Engineering \& Structural Dynamics, Vol. 41, No. 3, pp. 531-547.

FEMA (2004). FEMA P450: NEHRP Recommended Provisions and Commentary for Seismic Regulations for New Buildings and Other Structures, Federal Emergency Management Agency, Washington, USA.

FEMA (2009). FEMA P695: Quantification of Building Seismic Performance Factors, Federal Emergency Management Agency, Washington, USA.

Goulet, C.A., Haselton, C.B., Mitrani-Reiser, J., Beck, J.L., Deierlein, G.G., Porter, K.A. and Stewart, J.P. (2007). "Evaluation of the seismic performance of a code-conforming reinforced-concrete frame building-from seismic hazard to collapse safety and economic losses", Earthquake Engineering \& Structural Dynamics, Vol. 36, No. 13, pp. 1973-1997.

Han, S.W., Moon, K.H. and Chopra, A.K. (2010). "Application of MPA to estimate probability of collapse of structures", Earthquake Engineering \& Structural Dynamics, Vol. 39, No. 11, pp. 1259-1278.

Haselton, C.B., Liel, A.B., Deierlein, G.G., Dean, B.S. and Chou, J.H. (2010). "Seismic collapse safety of reinforced concrete buildings. I: Assessment of ductile moment frames", Journal of Structural Engineering, ASCE, Vol. 137, No. 4, pp. 481-491.

Ibarra, L.F., Medina, R.A. and Krawinkler, H. (2005). "Hysteretic models that incorporate strength and stiffness deterioration", Earthquake Engineering \& Structural Dynamics, Vol. 34, No. 12, pp. 1489-1511.

Ibarra, L.F. and Krawinkler, H. (2011). "Variance of collapse capacity of SDOF systems under earthquake excitations", Earthquake Engineering \& Structural Dynamics, Vol. 40, No. 12, pp. 1299-1314.

Jäger, C. and Adam, C. (2013). "Influence of collapse definition and near-field effects on collapse capacity spectra", Journal of Earthquake Engineering, Vol. 17, No. 6, pp. 859-878.

Kato, B.A. (Ye, L.P. and Pei, X.Z., Trans.) (2010). EarthquakeResistant Design Method for Buildings Based on Energy Balance, Tsinghua University Press, Beijing, China.
Kircher, C.A., Reitherman, R.K., Whitman, R.V. and Arnold, C. (1997). "Estimation of earthquake losses to buildings", Earthquake Spectra, Vol. 13, No. 4, pp. 703-720.

Kiureghian, A.D. and Ditlevsen, O. (2009). "Aleatory or epistemic? Does it matter?", Structural Safety, Vol. 31, No. 2, pp. 105-112.

Krawinkler, H. and Zareian, F. (2007). "Prediction of collapse-How realistic and practical is it, and what can we learn from it? ", The Structural Design of Tall and Special Buildings, Vol. 16, No. 5, pp. 633-653.

Lee, L.H., Han, S.W. and Oh, Y.H. (1999). "Determination of ductility factor considering different hysteretic models", Earthquake Engineering \& Structural Dynamics, Vol. 28, No. 9, pp. 957-977.

Liel, A.B., Haselton, C.B. and Deierlein, G.G. (2010). "Seismic collapse safety of reinforced concrete buildings. II: Comparative assessment of nonductile and ductile moment frames", Journal of Structural Engineering, ASCE, Vol. 137, No. 4, pp. 492-502.

Lu, X.Z., Ye, L.P., Ma, Y.H. and Tang, D.Y. (2012). "Lessons from the collapse of typical RC frames in Xuankou School during the great Wenchuan Earthquake", Advances in Structural Engineering, Vol. 15, No. 1, pp. 139-154.

Luco, N., Ellingwood, B.R., Hamburger, R.O., Hooper, J.D., Kimball, J.K. and Kircher, C.A. (2007). "Risk-targeted versus current seismic design maps for the conterminous United States", Proceedings of Structural Engineers Association of California 2007 Convention, Lake Tahoe, USA.

Mahin, S.A. and Bertero, V.V. (1976). "Nonlinear seismic response of a coupled wall system", Journal of the Structural Division, ASCE, Vol. 102, No. 9, pp. 1759-1780.

Malhotra, P.K. (1999). "Response of buildings to near-field pulselike ground motions", Earthquake Engineering \& Structural Dynamics, Vol. 28, No. 11, pp. 1309-1326.

Mehanny, S.S. (1999). Modeling and Assessment of Seismic Performance of Composite Frames with Reinforced Concrete Columns and Steel Beams, PhD. Thesis, Department of Civil and Environment Engineering, Stanford University, Stanford, USA.

Miranda, E. and Akkar, S.D. (2003). "Dynamic instability of simple structural systems”, Journal of Structural Engineering, ASCE, Vol. 129, No. 12, pp. 1722-1726.

Miranda, E. and Ruiz-García, J. (2002). "Evaluation of approximate methods to estimate maximum inelastic displacement demands", Earthquake Engineering \& Structural Dynamics, Vol. 31, No. 3, pp. 539-560.

Rahnama, M. and Krawinkler, H. (1993). Effects of Soft Soil and Hysteresis Model on Seismic Demands, Blume Earthquake Engineering Center Report No. 108, Department of CEE, Stanford University: Stanford, USA.

Riddell, R. (2008). "Inelastic response spectrum: early history", Earthquake Engineering \& Structural Dynamics, Vol. 37, No. 8, pp. 1175-1183.

Shafei, B., Zareian, F. and Lignos, D.G. (2011). "A simplified method for collapse capacity assessment of moment-resisting 
frame and shear wall structural systems", Engineering Structures, Vol. 33, No. 4, pp. 1107-1116.

Takizawa, H. and Jennings, P.C. (1980). "Collapse of a model for ductile reinforced concrete frames under extreme earthquake motions", Earthquake Engineering \& Structural Dynamics, Vol. 8, No. 2, pp. 117-144.

Tang, B., Lu, X., Ye, L.P. and Shi, W. (2011). "Evaluation of collapse resistance of RC frame structures for Chinese schools in seismic design categories B and C", Earthquake Engineering and Engineering Vibration, Vol. 10, No. 3, pp. 369-377.

Tong, G. and Zhao, Y. (2007). "Seismic force modification factors for modified-Clough hysteretic model", Engineering Structures, Vol. 29, No. 11, pp. 3053-3070.

Vamvatsikos, D. and Cornell, C.A. (2002). "Incremental dynamic analysis", Earthquake Engineering \& Structural Dynamics, Vol. 31, No. 3, pp. 491-514.

Vamvatsikos, D. and Cornell, C.A. (2004). "Applied incremental dynamic analysis", Earthquake Spectra, Vol. 20, No. 2, pp. 523-553.

Vamvatsikos, D. and Cornell, C.A. (2005). "Direct estimation of seismic demand and capacity of multidegree-of-freedom systems through incremental dynamic analysis of single degree of freedom approximation", Journal of Structural Engineering, ASCE, Vol. 131, No. 4, pp. 589-599.

Vian, D. and Bruneau, M. (2003). "Tests to structural collapse of single degree of freedom frames subjected to earthquake excitations", Journal of Structural Engineering, ASCE, Vol. 129, No. 12, pp. 1676-1685.
Williamson, E.B. (2003). "Evaluation of damage and P- $\Delta$ effects for systems under earthquake excitation", Journal of Structural Engineering, ASCE, Vol. 129, No. 8, pp. 1036-1046.

Ye, L.P., Lu, X.Z. and Li, Y. (2010). "Design objectives and collapse prevention for building structures in mega-earthquake", Earthquake Engineering and Engineering Vibration, Vol. 9, No. 2, pp. 189-199.

Ye, L.P., Ma, Q.L., Miao, Z.W., Guan, H. and Zhuge, Y. (2013). "Numerical and comparative study of earthquake intensity indices in seismic analysis", The Structural Design of Tall and Special Buildings, Vol. 22, No. 4, pp. 362-381.

Zareian, F. and Krawinkler, H. (2007). "Assessment of probability of collapse and design for collapse safety", Earthquake Engineering \& Structural Dynamics, Vol. 36, No. 13, pp. 1901-1914.

Zareian, F. and Krawinkler, H. (2010). "Structural system parameter selection based on collapse potential of buildings in earthquakes", Journal of Structural Engineering, ASCE, Vol. 136, No. 8, pp. 933-943.

Zareian, F., Krawinkler, H., Ibarra, L. and Lignos, D. (2010). "Basic concepts and performance measures in prediction of collapse of buildings under earthquake ground motions", The Structural Design of Tall and Special Buildings, Vol. 19, No. 1-2, pp. 167-181.

Zhao, B., Taucer, F. and Rossetto, T. (2009). "Field investigation on the performance of building structures during the 12 May 2008 Wenchuan earthquake in China", Engineering Structures, Vol. 31, No. 8, pp. 1707-1723. 
